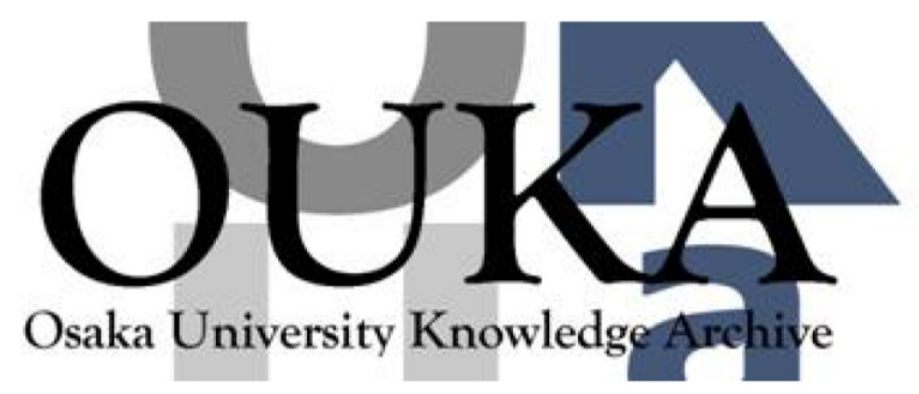

\begin{tabular}{|c|l|}
\hline Title & $\begin{array}{l}\text { Pore size dependence of field emission from } \\
\text { nanoscale porous carbon }\end{array}$ \\
\hline Author(s) & $\begin{array}{l}\text { Ojima, Masahiro; Hiwatashi, Shohei; Araki, } \\
\text { Huzihiro et al. }\end{array}$ \\
\hline Citation & $\begin{array}{l}\text { Applied Physics Letters. 88(5) p.053103- } \\
\text { p.053103 }\end{array}$ \\
\hline Issue Date & $2006-01-30$ \\
\hline oaire:version & VoR \\
\hline URL & https://hdl. handle. net/11094/75657 \\
\hline rights & \\
\hline Note & \\
\hline
\end{tabular}

Osaka University Knowledge Archive : OUKA

https://ir. Library. osaka-u. ac. jp/

Osaka University 


\section{Pore size dependence of field emission from nanoscale porous carbon}

Cite as: Appl. Phys. Lett. 88, 053103 (2006); https://doi.org/10.1063/1.2170436

Submitted: 28 March 2005. Accepted: 09 December 2005. Published Online: 30 January 2006

M. Ojima, S. Hiwatashi, H. Araki, A. Fujii, M. Ozaki, and K. Yoshino

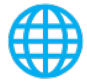

\section{ARTICLES YOU MAY BE INTERESTED IN}

Field emission behavior of carbon nanotube field emitters after high temperature thermal annealing

AIP Advances 4, 077110 (2014); https://doi.org/10.1063/1.4889896

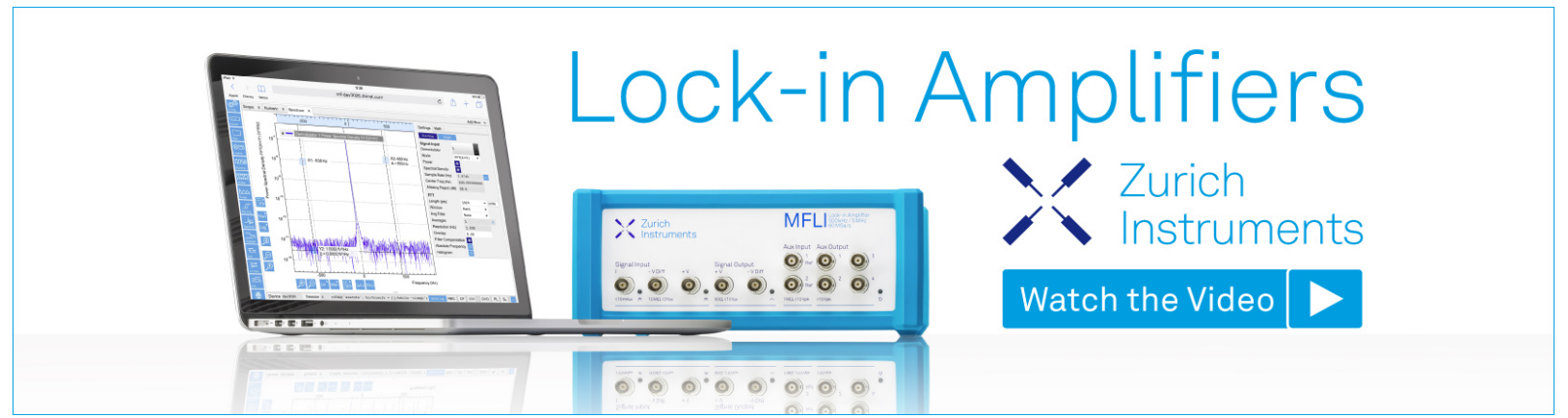




\title{
Pore size dependence of field emission from nanoscale porous carbon
}

\author{
M. Ojima, S. Hiwatashi, H. Araki, A. Fujii, ${ }^{\text {a) }}$ M. Ozaki, and K. Yoshino \\ Department of Electronic Engineering, Graduate School of Engineering, Osaka University, \\ 2-1 Yamadaoka, Suiita-shi, Osaka 565-0871, Japan
}

(Received 28 March 2005; accepted 9 December 2005; published online 30 January 2006)

Carbon inverse opals with three-dimensional nanoporous structures are fabricated by a template method using synthetic opals formed by the sedimentation of $\mathrm{SiO}_{2}$ spheres. The pore size of the carbon inverse opals ranges widely from about $74 \mathrm{~nm}$ to $550 \mathrm{~nm}$ depending on the diameter of the $\mathrm{SiO}_{2}$ spheres. These nanoporous structures of carbon exhibit excellent characteristics as electron emitters. As the pore size of porous carbon decreases, the effective emission area of field emission increases. The main emitter sites of porous carbon are interpreted to be the edges formed in the boundary of the neighboring pores. The emission characteristics have drastically improved upon heat treatment at high temperatures (about $2760^{\circ} \mathrm{C}$ ). (C) 2006 American Institute of Physics. [DOI: $10.1063 / 1.2170436$ ]

Porous carbons with nanopores have attracted much attention due to their potential applications, such as electrodes of a fuel cell, hydrogen storage, and electric double-layer capacitors. $^{1-4}$

Carbon inverse opals with various pore sizes have been fabricated by a template method using synthetic opals, and their pore sizes were controllable in nano-order. ${ }^{5-7}$ These materials were expected to have unique and useful properties as optical and electrical devices, because they had a periodic porous nanostructure with a periodicity of the order of optical wavelengths.

Carbon-based electron field emitters have won worldwide attention as a new electron source for a flat panel display. ${ }^{8}$ Many researchers had an interest in carbon nanotube arrays as an excellent source for field emission (FE) ${ }^{9-11}$ However, fabrication processes of the controlled carbon nanotube arrays were difficult and expensive. The porous carbon fabricated by the template method has a large domain with periodical and regular voids, and its void density is controllable. Therefore, we can easily control the emission sites density. In addition, fabrication processes of the porous carbon are very easy. A strategy to utilize the carbon inverse opals as the field emitter has never been studied, to our knowledge. In this study, the FE characteristics in several porous carbons are studied and the effective emitting area is discussed.

Synthetic opals were fabricated by sedimentation of the suspension of monodisperesed $\mathrm{SiO}_{2}$ spheres of 74, 120, 300, and $550 \mathrm{~nm}$ in diameter and sintered at $700-900{ }^{\circ} \mathrm{C}$. These opals contain interconnecting octahedral voids whose diameters depend on the diameter of $\mathrm{SiO}_{2}$ spheres. Pristine products were prepared by infiltrating starting materialsphenolic resin-into the voids in synthetic opals and then pyrolyzing them at $600{ }^{\circ} \mathrm{C}$ in a high-purity $\mathrm{Ar}$ atmosphere for carbonization of the samples. Subsequently, the $\mathrm{SiO}_{2}$ spheres in the products were removed by immersing them into the aqueous solution of hydrofluoric acid. These samples were pyrolyzed at $1100{ }^{\circ} \mathrm{C}$ for $1 \mathrm{~h}$ in a high-purity Ar atmosphere again. The effect of pyrolysis at high temperatures was carried out with SDS-46, SHINSEI.

\footnotetext{
${ }^{a)}$ Electronic mail: afujii@ele.eng.osaka-u.ac.jp
}

Electron microscope images of the morphology of samples were obtained by a scanning electron microscope (SEM) (S-5000, Hitachi) and a transmission electron microscope (TEM) (H-8100, Hitachi).

The FE measurements were performed for the porous carbon as an emitter in a high vacuum chamber (about $10^{-7}$ Torr). We used a tungsten probe with a diameter of $500 \mu \mathrm{m}$ as an anode. The cross-sectional area of the anode was $1.96 \times 10^{-7} \mathrm{~m}^{2}$. FE current density-electric field characteristics were studied for various distances $(z)$ between the anode and the porous carbon. The emission characteristics have been found to be nearly the same for all surface areas studied, supporting the uniformity of the surface.

Figures 1(a) and 1(b) show the SEM images of the porous carbon prepared from $\mathrm{SiO}_{2}$ spheres of 550 and $120 \mathrm{~nm}$ in diameter, respectively. These figures revealed that the periodicity and, therefore, the size of voids were approximately consistent with the diameter of spheres of synthetic opals.

Figure 2 shows the TEM image and the electron diffraction pattern of the porous carbon with $550 \mathrm{~nm}$ pore size. The TEM image is rather complicated but can be explained as one corresponding to a well-arranged three-dimensional pore structure. The electron diffraction exhibits a halo pattern, and therefore demonstrates that the crystalline structure of the porous carbon pyrolyzed at $1100{ }^{\circ} \mathrm{C}$ is amorphous.

Figure 3(a) shows the FE current density $(J)$-electric field $(E)$ characteristics for various porous carbons with different pore sizes ranging between 74 and $550 \mathrm{~nm}$, as mentioned above, when $Z=40 \mu \mathrm{m}$. The threshold electric field was decreased by decreasing the pore size. These $J-E$ characteristics seem to be saturated in a current density range of $J>10^{-3}-10^{-5}\left(\mathrm{~A} / \mathrm{cm}^{2}\right)$. Similar phenomena were also observed in characteristics from the carbon nanotube array. ${ }^{12,13}$

These $J-E$ characteristics were analyzed by the FowlerNordheim (FN) equation for FE. The emission current density $J$ as a function of the local electric field at the emitter surface $F$ is given by $J=\left(A F^{2} / \phi\right) \exp \left(-B \phi^{3 / 2} / F\right)$ $\times\left(\mathrm{A} \mathrm{m}^{-2}\right) \quad$ with $\quad A=1.56 \times 10^{-10}\left(\mathrm{~A} \mathrm{~V}^{-2} \mathrm{eV}\right), \quad B=6.83$ $\times 10^{9}\left(\mathrm{~V} \mathrm{eV}^{-3 / 2} \mathrm{~m}^{-1}\right)$, and $\phi$ as the work function. Figure 3(b) shows the FN plots for the observed current-voltage characteristics. Data points in a low-voltage range of the FN plots were approximately on a straight line, which indicates 

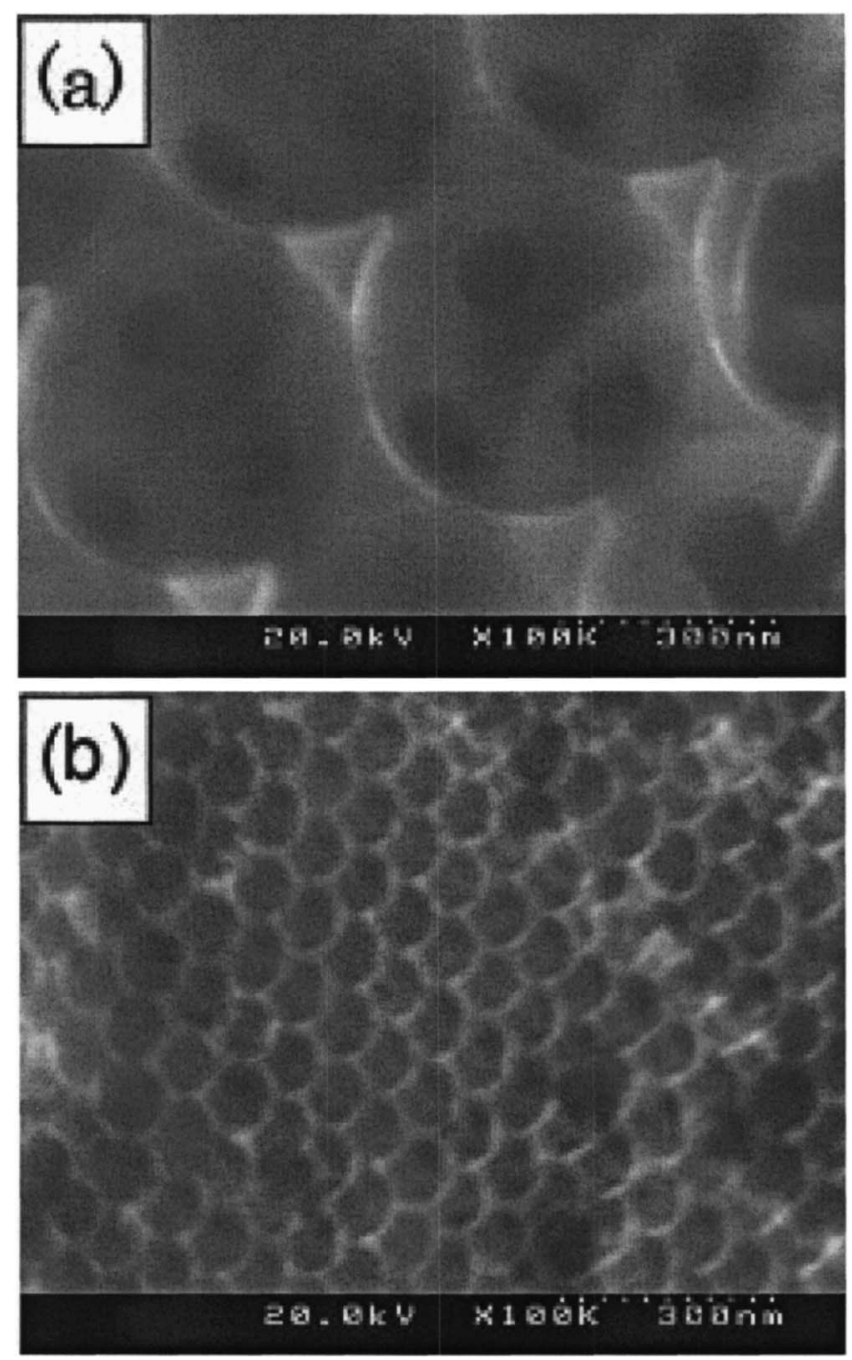

FIG. 1. SEM images of porous carbon prepared from $\mathrm{SiO}_{2}$ sphere of (a) 550 $\mathrm{nm}$ and (b) $120 \mathrm{~nm}$.

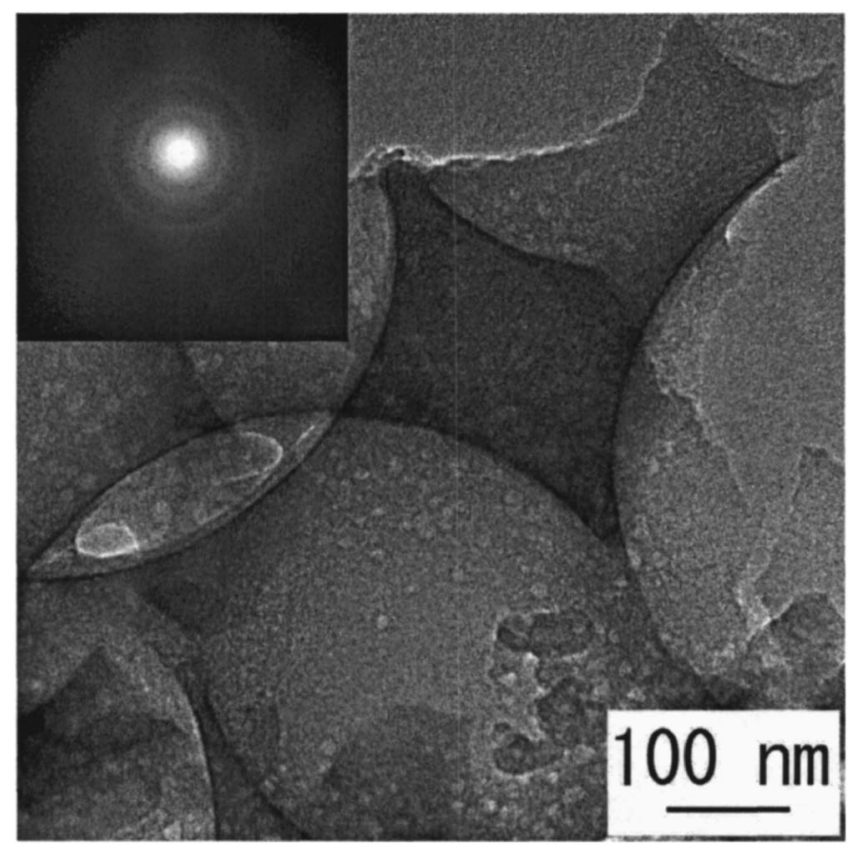

FIG. 2. TEM image and the electron diffraction pattern of porous carbon.
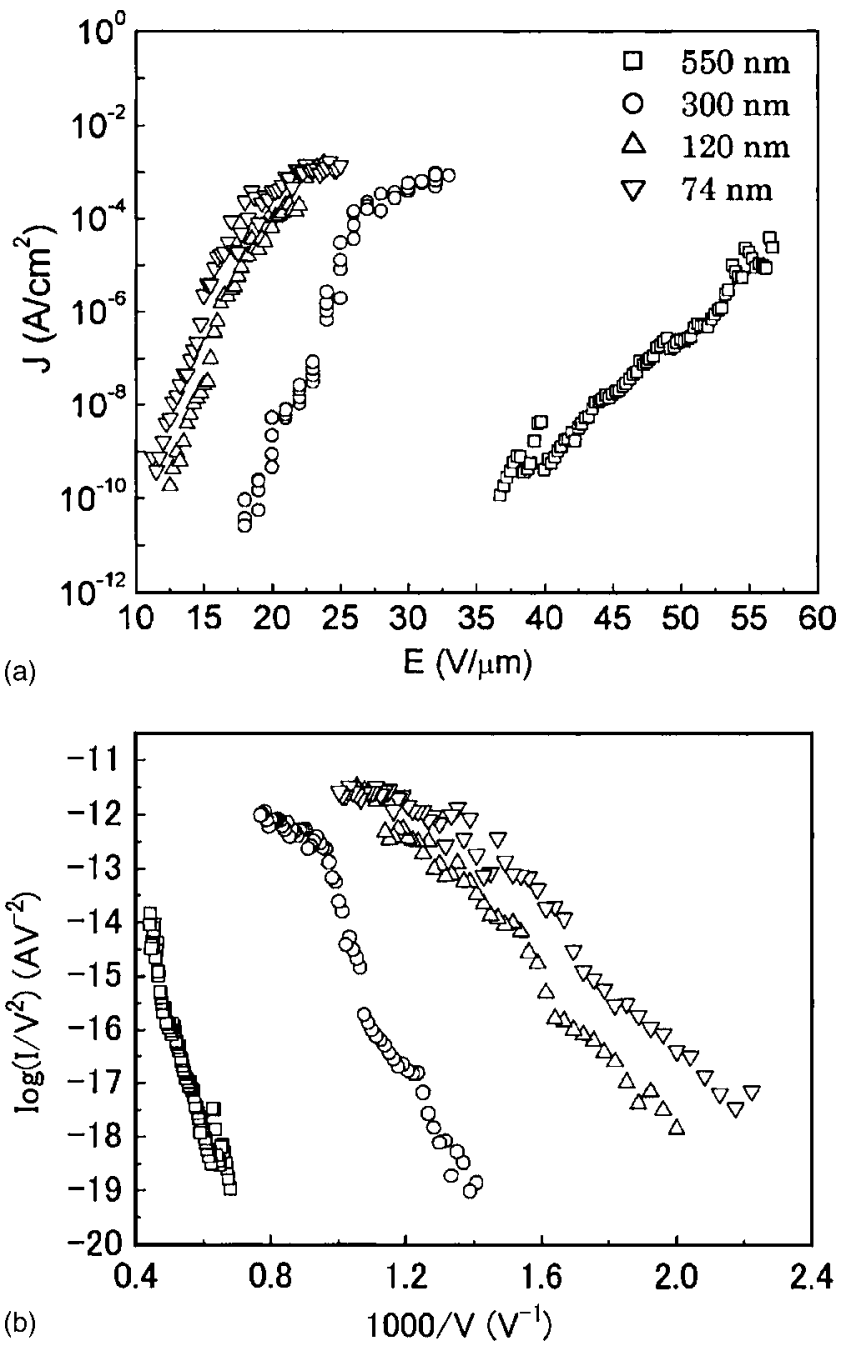

FIG. 3. (a) FE $J-E$ characteristics for the electrodes distance of $40 \mu \mathrm{m}$. (b) FN plots of the current-voltage characteristics.

that the analysis of the data utilizing FN equation is reasonable. From the slope and the ordinate intercept of the straight line, we estimated the field enhancement factor and the effective emission area with a work function taken equal to that of graphite $(5 \mathrm{eV})$. It was found that with decreasing pore size, both the field enhancement factor and the effective area became larger.

Figure 4 indicates that there is a reciprocal linear relationship between the pore size and the effective emission area on a logarithmic scale. The slope was about -2 , therefore, the relationship of pore size $(x)$ and the effective area

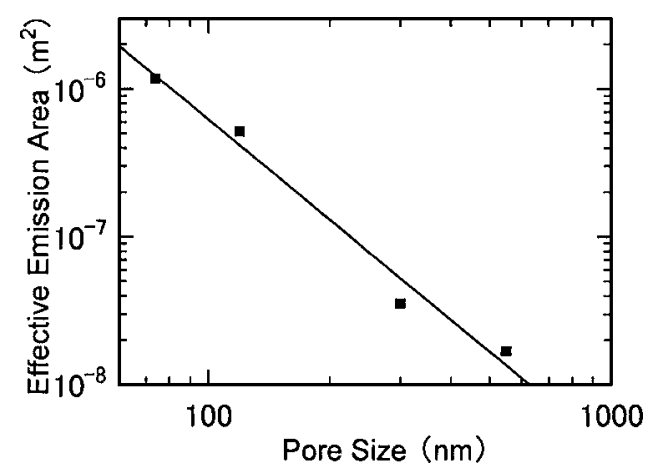

FIG. 4. Dependence of effective emission area on pore size. 

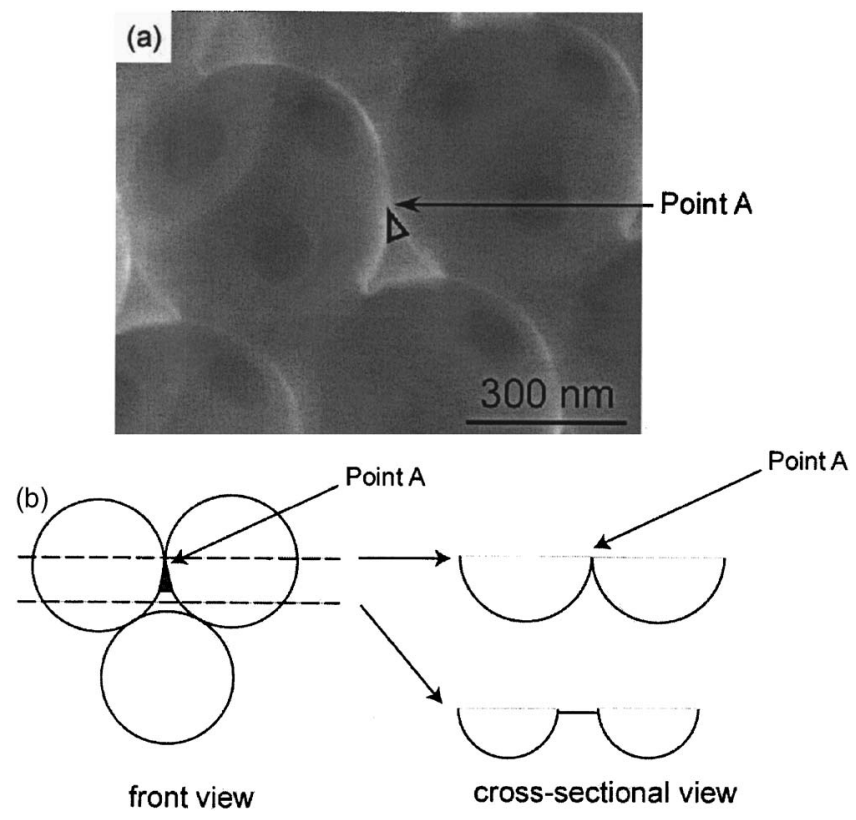

FIG. 5. Emission site of porous carbon.

(y) was expressed by the relation of $y=K / x^{2}$, where $K$ is a constant factor which is independent of pore size over a range of $x$ longer than $70 \mathrm{~nm}$. FE is expected to be caused at the site of the most concentrated electric field in front of the pore surface. Point A in Fig. 5(a) corresponds to a sharp edge formed in the boundary of the neighboring pores. The edge in Point A is shown schematically in Fig. 5(b) by illustrations of the front view and the cross-sectional view in the boundary of Fig. 5(a). Therefore, Point A is the most promising candidate for the emission sites. There are six sites, like Point A, located in each pore. It is suggested that the area of Point A was not changed for all pore size, and FE was caused mainly at the sharp edge in the boundary of the pores. With decreasing pore size (diameter of the pore size; $r$ ), the total number of Point $\mathrm{A}$ - in a unit area-increase in proportion to $r^{-2}$, which coincides with the result of Fig. 5 .

In this study, all samples were in the amorphous state. The porous carbon was well crystallized by the heat treatment at the higher temperature. Much improved FE characteristics by the heat treatment of porous carbon at the higher temperature $\left(2760^{\circ} \mathrm{C}\right)$ were found, as indicated in Fig. 6.

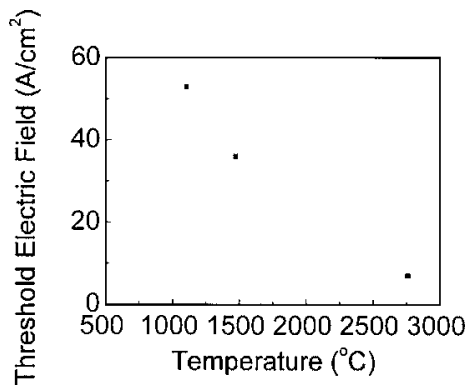

FIG. 6. Dependence of threshold electric field on temperature.

That is, for example, the threshold field was drastically reduced.

In this study, periodic nanoporous carbons-having several pore sizes-were prepared using synthetic opals. Then, we demonstrated excellent FE characteristic of the periodic nanoporous carbon and indicated that the main emission site is the sharp edge formed in the boundary of the neighboring pores, and the density of the emission site increased proportionally to the pore numbers per unit surface area.

The authors would like to express sincere thanks to Dr. T. Nakayama and Professor K. Niihara for the use of facilities of the electron microscopy.

${ }^{1}$ H. Take, T. Matsumoto, and K. Yoshino, Synth. Met. 135, 731 (2003).

${ }^{2}$ S. Shiraishi, H. Kurihara, H. Tsubota, A. Oya, Y. Soneda, and Y. Yamada, Electrochem. Solid-State Lett. 4, A5 (2001).

${ }^{3}$ S. Han, Y. Yun, K.-W. Park, Y.-E. Sung, and T. Hyeon, Adv. Mater. (Weinheim, Ger.) 15, 1922 (2003).

${ }^{4}$ J. S. Yu, S. Kang, S. B. Yoon, and G. Chai, J. Am. Chem. Soc. 124, 9382 (2002).

${ }^{5}$ A. A. Zakhidov, R. H. Baughman, Z. Iqbal, C. Cui, K. Khayrullin, S. O. Dantas, J. Marti, and V. G. Ralchenko, Science 282, 897 (1998).

${ }^{6}$ K. Yoshino, H. Kajii, Y. Kawagishi, M. Ozaki, A. A. Zakhidov, and R. H. Baughman, Jpn. J. Appl. Phys., Part 1 38, 4926 (1999).

${ }^{7}$ H. Take, T. Matsumoto, S. Hiwatashi, T. Nakayama, K. Niihara, and K. Yoshino, Jpn. J. Appl. Phys., Part 1 43, 4453 (2004).

${ }^{8}$ A. A. Talin, T. E. Felter, T. A. Friedmann, J. P. Sullivan, and M. P. Siegal, J. Vac. Sci. Technol. A 14, 1719 (1996).

${ }^{9}$ W. A. de Heer, A. Chatelain, and D. Ugrate, Science 270, 1179 (1995).

${ }^{10}$ J. M. Bonard, J. P. Salvetat, T. Stockli, W. A. de Heer, L. Forro, and A. Chatelain, Appl. Phys. Lett. 73, 918 (1998).

${ }^{11}$ S. Fan, M. G. Chapline, N. R. Franklin, T. W. Tombler, A. M. Cassell, and H. Dai, Science 283, 512 (1999).

${ }^{12}$ H. Araki, T. Katayama, and K. Yoshino, Appl. Phys. Lett. 79, 2636 (2001).

${ }^{13}$ K. Kamide, H. Araki, and K. Yoshino, Jpn. J. Appl. Phys., Part 1 42, 1539 (2004). 